
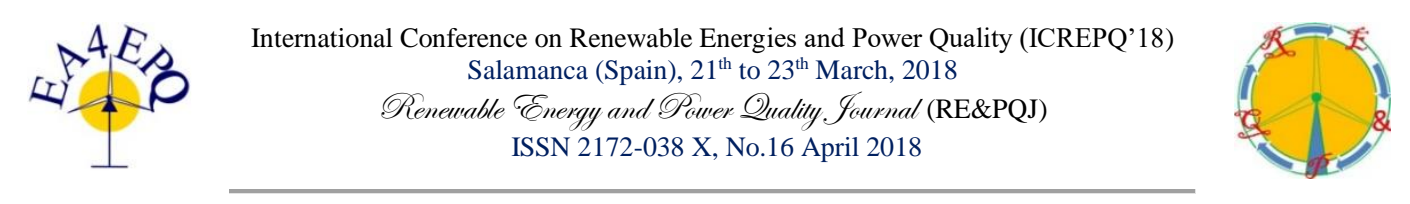

\title{
A First Approach on the Impact of Distributed Generation and network topology on Studies of Voltage Sags
}

\author{
A. C. L. Ramos ${ }^{1,4}$, A. J. Batista ${ }^{2}$, R. C. Leborgne ${ }^{3}$, E. G. Domingues ${ }^{4}$, W. P. Calixto ${ }^{4}$. \\ ${ }^{1}$ CELG Generation and Transmission S.A., Brazil \\ e-mail: alessandro@ celggt.com; \\ ${ }^{2}$ School of Electrical and Computer Engineering, Federal University of Goias \\ e-mail: batista@eee.ufg.br \\ ${ }^{3}$ Department of Electrical Engineering, Federal University of Rio Grande do Sul \\ e-mail: rcl@ece.ufrgs.br

\begin{abstract}
${ }^{4}$ Nucleus of Studies Experimental and Technological, Electrotechnical Department - Federal Institute of Goias, Brazil e-mail: wpcalixto@ieee.org; elder.domingues@ifg.edu.br
\end{abstract}

\begin{abstract}
An analysis of the distributed generation (DG) and network topology impact on studies of voltage sags caused by system faults is presented. The simulation of 62 case studies of phase-to-ground faults on $13.8,69,138$ and $230 \mathrm{kV}$ transmission lines were performed and the voltage of a $380 \mathrm{~V}$ sensitive industrial busbar client was monitored. These lines are part of the electrical system of the city of Goiania, Brazil. For each case study, different fault positions were simulated by considering different DG levels connected to the consumer busbar. Long-term simulation scenarios were obtained by the Monte Carlo method and analyzed based on their cumulative distribution functions and probability density curves of voltage sags. This is one major contribution of this work.
\end{abstract}

Key Words - Power quality, voltage sags, distributed generation, Monte Carlo method, Network Topology.

\section{Introduction}

$\mathrm{I}_{\mathrm{s}}^{\mathrm{s}}$ $\mathrm{N}$ an evolving world, electrical loads and processes demand sources of power that are free from distortion and within certain patterns. Voltage sags have been the main source of problems that affects industrial consumers [1], [2]. Their causes include short-circuits (i.e., faults), transformer energization, motor starting and sudden load changes. However, shortcircuits are the cause of the most severe voltage sags in transmission and distribution networks [1]. Voltage sag is a reduction in rms value of source voltage, in one or more phases of the system, to values between $10 \%$ and $90 \%$ for periods of time between half cycle and 1 minute [3] and it characterized by its magnitude (the retained voltage), phase-angle jump, unbalance and duration [1]. There are many factors that influence voltage sags and some of them have received considerable attention from the researchers as, for example: the fault characteristics (location [4], type [4], impedance [5], [22] and fault Distribution [6]), pre-fault voltage [7], fault rate [8], protection system [9], reclosing system [9] and the system generation level [2], [23].

Another area of emerging interest for research is distributed generation (DG). Any power source that is directly connected to the distribution grid or end user system can be defined as DG [10]. These kinds of sources have been re-emerging in the entire world [11], mainly due to environmental questions. Besides, DG may be seen as a solution for many power quality problems, such as those related to voltage sags [2], [11]. This study considers that the DG stays connected to the system when a fault occurs.

Distribution grids are not commonly designed to accommodate distributed generators, as they are designed to supply electrical loads. Moreover, the connection of the DG changes the radial topology of the distribution networks [12]. Therefore, before the installation of DGs, a previous study on the impact of these systems on the power grid must be done. Aspects such as voltage regulation, power quality and shortcircuit level must be considered. For example, the distribution networks are characterized by the short-circuit level because the maximum fault current determines the rated value of the substation equipment. Therefore, the increase of the shortcircuit capacity due to the connection of the DG should not exceed the maximum values for the safe and reliable operation of the substation. This fact limits the use of DG in distribution networks to sources up to $10 \mathrm{MVA}$ [12].

A previous study showed the influence of DG on the magnitudes of voltage sags caused by faults [2]. However, a prospective analysis, in probabilistic terms, for an individual consumer was not made. the topology of the network was also not considered in quantitative studies of voltage sags per year.

This work presents a research based on simulations, where the influence of DG on the magnitudes and frequency distributions of voltage sags caused by faults, at a sensitive industrial busbar consumer, is analyzed. The software chosen for simulation is the ANAFAS [13], a well-known software 
used by Brazilian utilities to simulate faults in the frequency domain. Due to some limitations of this software, which will be described later on this paper, a computational tool was implemented. This tool, named ANAFAS-GUI, permits, for example, to run several cases with different fault locations and DG levels connected to the monitored consumer busbar. The simulations of 62 case studies were performed and the voltage of an industrial busbar consumer was monitored. For each case study, different fault positions were simulated by considering different DG levels connected to the high voltage side of the consumer busbar. In order to manipulate the simulation results, another specific computational tool was implemented. This tool performs a Monte Carlo analysis and treats data generated by ANAFAS-GUI for each level of DG.

\section{Theoretical Background}

Quantitative voltage sag studies can be performed by two different ways: (a) by considering the frequency distributions of voltage sags, according to the voltage sag magnitude and duration, or (b) by the probability density of the events [14].

These studies can be made by measurement or by simulation. The main advantages of each method are described in [1]. The high cost and long monitoring period result in that measurement methods are quite unaffordable [1], [14].

Three methods of simulation are available: (a) wave shape simulation; (b) dynamic simulation; and (c) fault simulation. The present study considers only the amplitude of voltage sags caused by faults and characterizes them by the least reminiscent voltage. Therefore, the fault simulation method is preferred here due to its simplicity and because it provides the required voltage sag magnitude. ANAFAS was the software used in the simulations. Previous studies show that this software can be readily used to simulate voltage sags with good accuracy [15].

Although many technologies are available, the most commonly used types of DG, at least in Brazil, are synchronous or asynchronous generators [16]. Particularly in this study, DG is based on synchronous generators and, in order to model these generators, some classical softwares are available. For example, ATP [17] has two types of time domain models that are applicable to voltage sags (models 14 and 59). Model 14 is suitable to small synchronous generators, which is the case of DG units, and model 59 to large ones. Model 14, as shown in Fig. 1, is similar to the frequency domain generator model used by ANAFAS. Fig. 1(a) shows an ideal voltage source in series with the positive sequence impedance, $\mathrm{Z}_{\mathrm{G}}$. Fig. 1(b) shows the zero sequence model, which includes the zero sequence impedance, $Z_{0 \mathrm{G}}$, and three times the neutral-to-ground impedance, $\mathrm{Z}_{\mathrm{nt}}$.

In the present study, the negative sequence impedance is considered to be equal to the positive sequence impedance. Also the resistive component of the impedances is considered negligible.

\section{Methodology}

There are two modes of simulation in the ANAFAS: the automatic mode and the interactive mode. Using the automatic mode, a 1 percent minimum step along transmission lines can be considered for sliding faults, but the fault impedance is always null. In interactive mode, the software permits, for a fixed fault position, to change the fault impedance. Therefore, both modes of simulation have limitations.

Besides, the ANAFAS does not allow to interactively insert generators at any busbar. With the goal of eliminate these limitations and also to improve the performance by the execution of various ANAFAS simulations in "background", a software was implemented in JAVA language. The implemented software, named ANAFAS-GUI, permits to run simulations with different fault positions, short-circuit types, fault impedances and DG levels at one or more system busbars.

Due to its great frequency of occurrence [2], only phase-toground faults in transmission lines are considered in this study. The grid comprises approximately 62 lines and 42 transformers and is shown in Fig. 2.

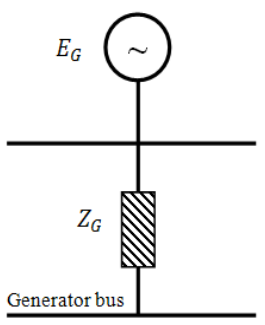

(a)

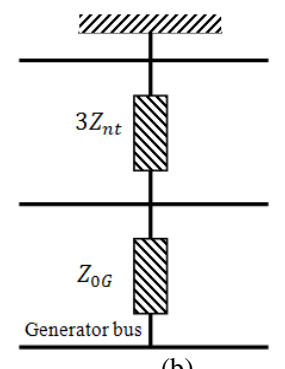

(b)
Fig.1. Synchronous generator model used by ANAFAS. (a) Positive sequence model. (b) Zero sequence model.

The industrial busbars consumers monitored is described in the top of Fig. 2 as "Client C busbar 9112" and "Client B busbar 9106". The end-user's transformers are included in the model. Short-circuits are simulated in all lines of the grid and vulnerability areas are not considered. The position of the fault is located along each line from zero to $100 \%$ in steps of $1 \%$. For each short-circuit position the impedance is assumed to be null, and the pre-fault voltages are assumed to be 1 p.u..

Another specific computational tool was implemented in MATLAB in order to manipulate the simulation results. This tool performs a Monte Carlo analysis and treats data generated by ANAFAS-GUI for each level of DG. The Monte Carlo algorithm is described as follows:

1. Define the busbar to be analyzed;

2. Define the number of scenarios for simulation;

3. Previously define the number of faults in the grid over one year, according to the fault rate in each system line. This procedure resulted in approximately 113 random faults per year;

4. For each year, randomly take the faulted line (FROM-bar and TO-bar). This line has any order between 1 and 62 . Then randomly take an integer which represents the fault position. This last task is repeated 113 times, resulting in 113 voltage values at end-user busbar. These values are then filtered in order to record only the voltage sag representing values;

5. After the previous item, the order of the year is incremented by one, and item 4 is repeated until the number of years reaches the total of user defined years.

In order to analyze only the effect of the DG level and network topology on the voltage sag assessment, the fault 
location is locked and only the DG level is varied for each fault location.

The data of the DGs were obtained on the basis of the data of a synchronous generator of 9 MVA [18]. Table I shows the transient $\left(X^{\prime}\right)$ and zero sequence $\left(X_{0}\right)$ reactances for the basic four DG units in a $100 \mathrm{MVA}, 13.8 \mathrm{kV}$ base. The power ratings of these DGs are in accordance to Brazilian Distribution Procedures [19], which indicates the power rating values for specific voltage levels. A previous study shows that the difference between the voltage sags magnitudes at a given busbar, obtained by using the subtransient and transient reactances in the generator model, is not significant [5]. So, each generator has only the transient and zero sequence reactance included in the model.

TABLE I

SYNCHRONOUS GENERATORS DATA.

\begin{tabular}{c|c|c|c|c|c}
\multicolumn{2}{|c|}{$\begin{array}{l}\text { Known data of a } \\
\text { 9 MVA unit [18] }\end{array}$} & \multicolumn{3}{c}{$\begin{array}{c}\text { DG units data on the basis of the 9 MVA } \\
\text { unit data in a 100 MVA, 13.8 kV base }\end{array}$} \\
\hline kVA & $\mathbf{9 0 0 0}$ & $\mathbf{9 0 0 0}$ & $\mathbf{1 0 0 0}$ & $\mathbf{2 2 5 0}$ & $\mathbf{4 5 0 0}$ \\
\hline kV & 6.9 & 13.8 & 13.8 & 13.8 & 13.8 \\
\hline $\boldsymbol{X}^{\prime}(\boldsymbol{p} . \boldsymbol{u} \%)$ & 40.8 & 113.33 & 1020 & 453.32 & 226.67 \\
\hline $\boldsymbol{X}_{\boldsymbol{0}}(\boldsymbol{p} . \boldsymbol{u} \%)$ & 12.5 & 50 & 450 & 200 & 100 \\
\hline
\end{tabular}

\section{Simulation Results}

Voltage sags are assessed in terms of their magnitudes and frequencies of occurrence. A first study shows the number of voltage sags obtained at an end-user busbar. For more detailed information, the study is performed for a period of 1,000 years.

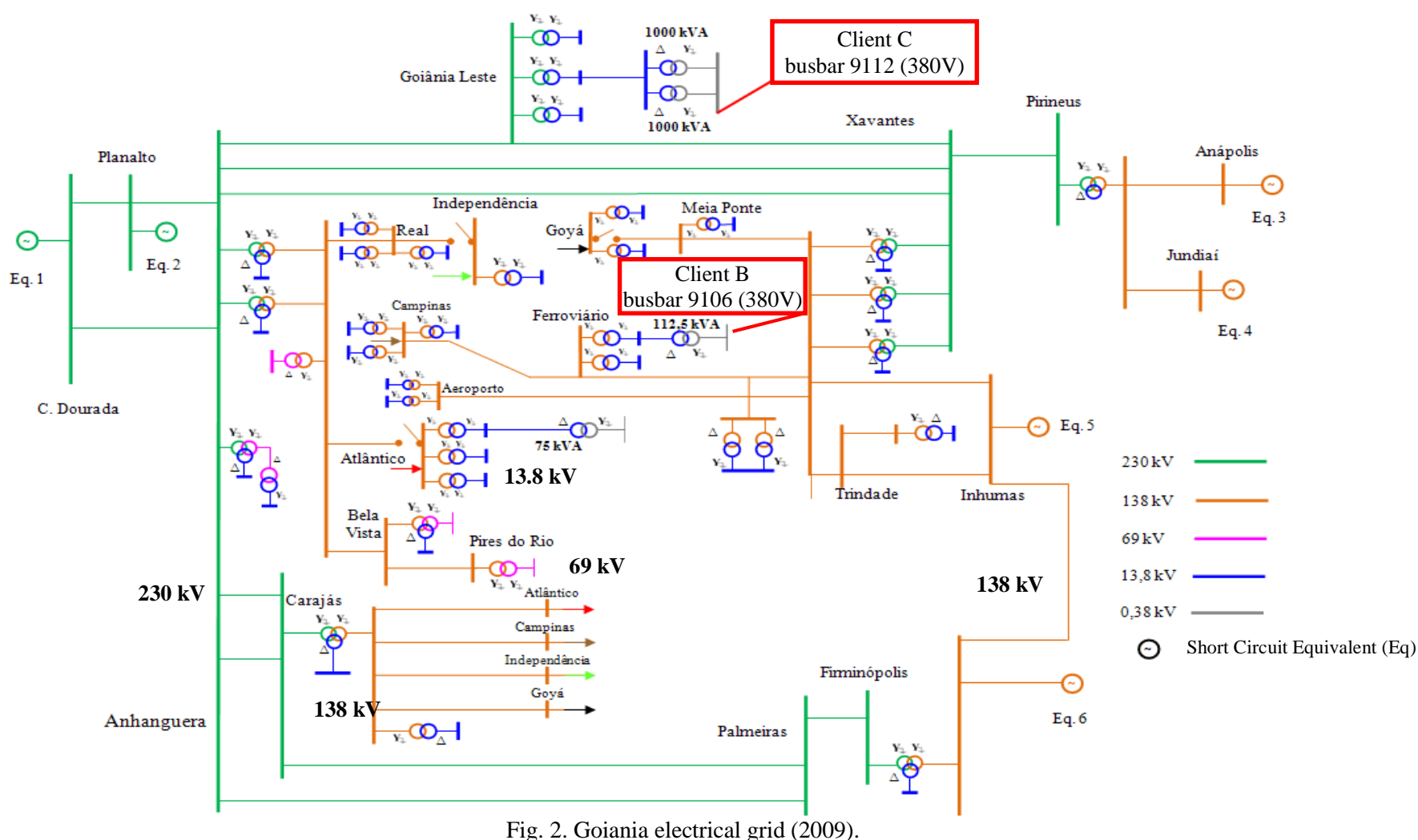

A second study shows the average number of voltage sags, obtained for an end-user busbar, according to the voltage sag magnitude [20] and the third study shows the impact of the network topology on the number of voltage sags for the same faults in the system.

The results illustrated in Figs. 3 to 5 show a general view of the performance of the end-user busbar in relation to voltage sags when there is not DG next to it. These results constitute a tool to assess the economic impact of voltage sags on sensitive loads, which is one of the major impacts of voltage sags [21]. Fig. 3 shows the random character of the number of voltage sag events. It is observed that the number of events varies year by year. However, the average value, given by (1), tends to a unique value.

$$
N_{\text {sag }}=\frac{1}{N_{\text {years }}} \sum_{i=1}^{N_{\text {years }}} X_{i}
$$

Where:

$N_{\text {sag }} \quad$ Average number of voltage sags in a $N_{\text {years }}$ scenario;

$X_{i} \quad$ Number of voltage sags during one year.

Fig. 3 shows the tendency of the average number of voltage sags expected per year. It can be seen that for 1,000 Monte Carlo simulations (SMC), the average number of voltage sags tends to be approximately 67 . It should be reminded that the analysis error is not zero, because the number of years of simulation is finite.

The information in Fig. 5 provides support to the correct choice of a device for voltage sag mitigation. For example, Fig. 4 shows that the end-user will have approximately 67 voltage sags in one year, but there is a $20 \%$ probability of the 
occurrence of 72 or more voltage sags during one year. Considering that the end-user grid is planned to operate for 30 years, the number of voltage sags exceeds 72 during 6 of these 30 years. Fig. 4 also shows the advantage of the Monte Carlo method for voltage sag studies. In Fig. 4 the information on number of voltage sags is obtained in a continuous manner, according to the cumulative distribution curve.

As shown earlier, the average number of voltage sags is 67. Fig. 5 shows that the most frequent voltage sags are those with magnitude from 0.70 to 0.90 p.u.. Within this range, voltage sags in the ranges of $0.70-0.85$ p.u. and $0.85-0.90$ p.u. have the same probability to occur.

Figs. 6 to 8 show the average number of voltage sags obtained for the same end-user busbar with a 4,500 kVA DG connected next to this busbar.

The consequence of the DG is a reduction of the number of voltage sags. Also, the voltage sags with magnitude in the range of 0.70-0.85 p.u. are now less frequent. Another aspect is the reduction of the number of voltage sags with a magnitude in the range of $0.50-0.70$ p.u..

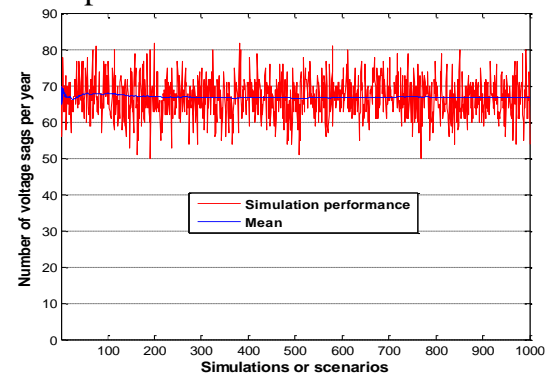

Fig. 3.Performance of the simulation and average number of voltage sags at 9112 busbar with $0 \mathrm{kVA}$ DG.

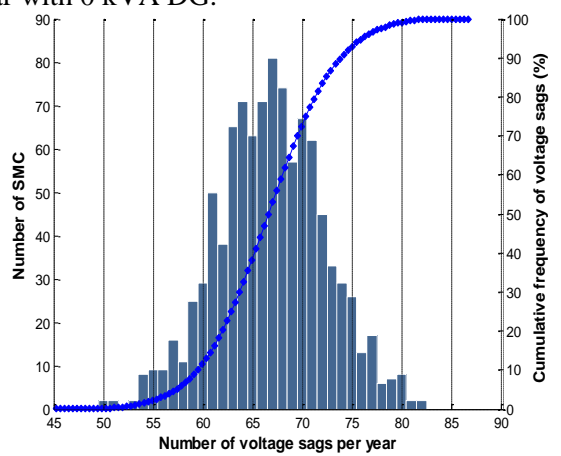

Fig. 4.Distribution and cumulative distribution of voltage sags at 9112 busbar with $0 \mathrm{kVA}$ DG.

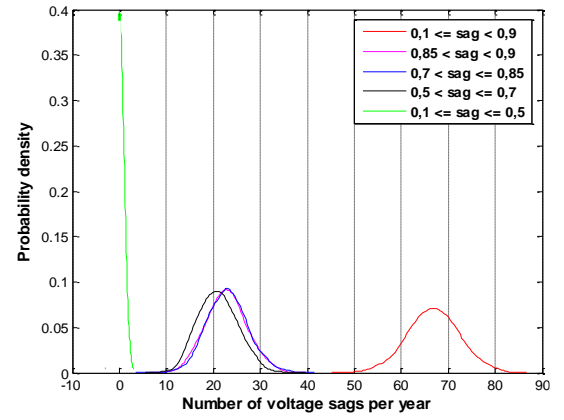

Fig. 5.Probability density of voltage sag classes at 9112 busbar with $0 \mathrm{kVA}$ DG.

Figs. 6 to 8 show the average number of voltage sags obtained for the same end-user busbar with a 4,500 kVA DG connected next to this busbar.

The generation levels of 1000 and 2250 were not plotted due to space limitations, however, they are being considered in table II and Figs 9 to 10 .

The insertion of a 4,500 kVA DG next to 9112 busbar decreases the average number of expected voltage sags to approximately 43, as shown in Figs. 6-10. This represents a difference of 24 voltage sags compared to the case without DG.

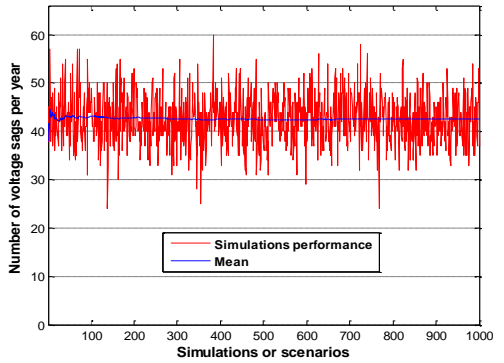

Fig. 6. Simulation performance and average number of voltage sags for 4,500 kVA DG at 9112 busbar.

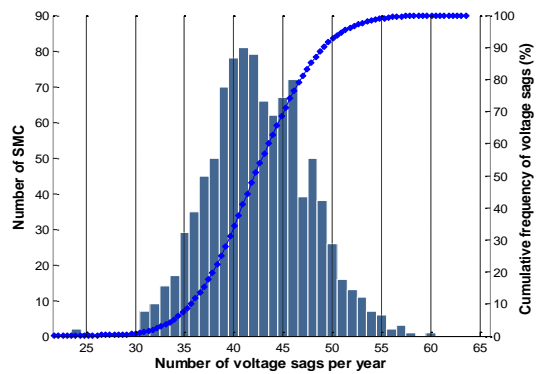

Fig. 7. Distribution and cumulative distribution of voltage sags for 4,500 kVA DG at 9112 busbar.

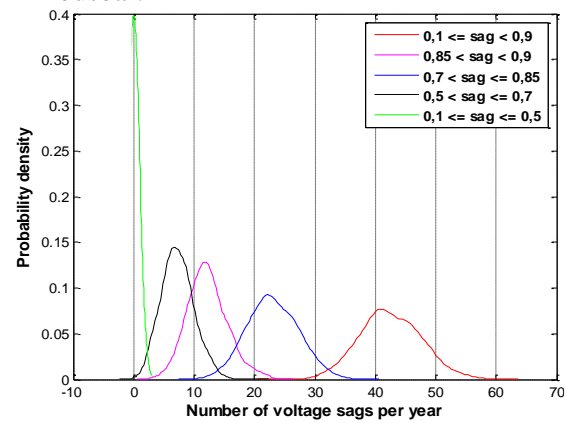

Fig. 8. Probability density of voltage sag classes for 4,500 kVA DG at 9112 busbar.

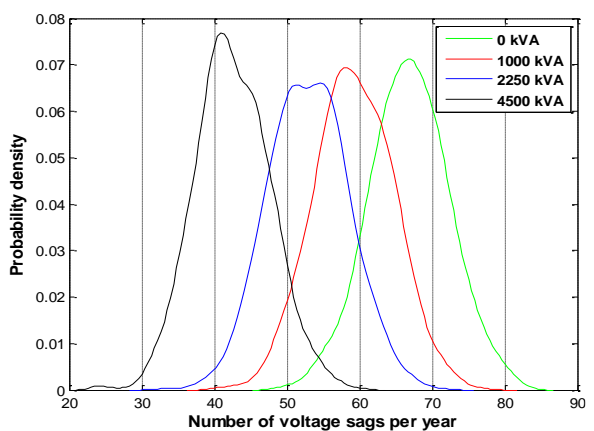

Fig. 9.Probability density of voltage sags for different levels of DG at 9112 busbar.

Fig. 8 shows that the most severe voltage sags, with amplitudes in the range of $0.10-0.50$ p.u., not occur next to the end-user busbar. Also, a reduction is obtained for voltage sags with magnitude in the classes of $0.50-0.70$ p.u. and 0.85 0.90 p.u.. However, the number of voltage sags with magnitude between 0.70 and 0.85 p.u. is equal to that found in the base case (i.e., without DG). 


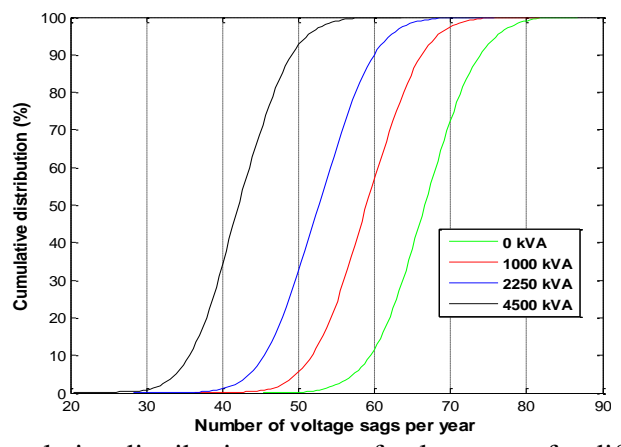

Fig. 10.Cumulative distribution curves of voltage sags for different DG DG at 9112 levels.

Figs. 9 and 10 show a comparative analysis of the simulated different DG levels next to the end-user busbar. These figures show, respectively, the probability density and cumulative distribution curves for different DG levels. Both these figures show a displacement to the left in the curve for a given DG level as this level increases. This indicates a reduction on the average number of voltage sags according to the increase of the DG level.

Table II summarizes the results obtained herein is busbar 9112. This table shows the average number of voltage sags at the end-user busbar, according to the DG levels and the voltage sag magnitude classes. From this table one can observe that, in general, the average number of voltage sags decreases when the DG level increases. There was no event for the class of more severe sags, from 0.1 to 0.5 p.u..

Table III shows the relative variation of the number of voltage sags, according to the voltage sag magnitude classes, for minimum and maximum level of DG. The relative variation, $\Delta N_{s a g}$, is calculated by (2).

TABLE II

NUMBER OF VOLTAGE SAGS AT END-USER BUSBAR ACCORDING TO DG LEVEL AND VOLTAGE SAG MAGNITUDE.

\begin{tabular}{c|c|c|c|c|c}
\multirow{2}{*}{$\begin{array}{c}\text { DG levels } \\
\text { (kVA) }\end{array}$} & \multicolumn{5}{|c}{ Voltage sag magnitude classes (p.u.) } \\
\cline { 2 - 6 } & $\mathbf{0 . 1 - 0 . 5}$ & $\mathbf{0 . 5 - 0 . 7}$ & $\mathbf{0 . 7 - 0 . 8 5}$ & $\mathbf{0 . 8 5 - 0 . 9}$ & $\mathbf{0 . 1 - 0 . 9}$ \\
\hline $\mathbf{0}$ & 0 & 21.028 & 23.036 & 22.779 & 66.843 \\
\hline $\mathbf{1 0 0 0}$ & 0 & 18.481 & 22.097 & 18.649 & 59.227 \\
\hline $\mathbf{2 2 5 0}$ & 0 & 12.468 & 23.831 & 16.627 & 52.926 \\
\hline $\mathbf{4 5 0 0}$ & 0 & 7.275 & 23.023 & 12.208 & 42.506
\end{tabular}

TABLE III

VOLTAGE SAG FREQUENCY VARIATION FOR ZERO AND 4,500 KVA DG.

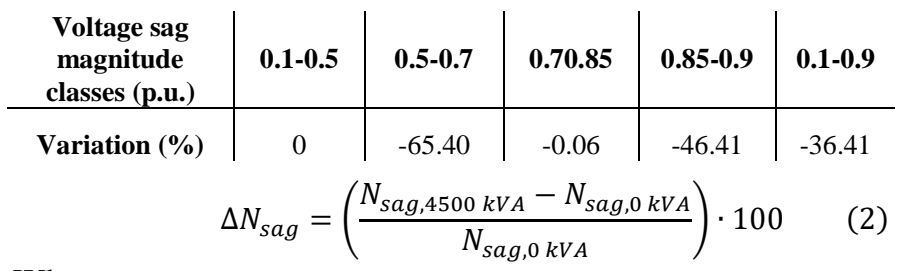

Where:

$\mathbf{N}_{s a g, 4500 \mathrm{kVA}}$ Number of voltage sags for 4,500 kVA DG level; $\mathrm{N}_{s a g, 0 \mathrm{kVA}}$ Number of voltage sags for zero DG level.

According to the last column of Table III the average variation on the number of voltage sags, for maximum and minimum DG, is $-36.41 \%$ and, for the range of $0.10-0.50$ p.u., there is no variation. Also, the most severe voltage sags, in the range of 0.5-0.7p.u., present an average reduction of $65.40 \%$.
Subsequently, the impact of the same levels of GD on another sensitive bar (9106) is shown, connected at a point in the system in which the network topology has changed.

Figs. 11 to 13 show the average number of voltage sags obtained for the same end-user busbar with a $0 \mathrm{kVA}$ DG connected next to this busbar.

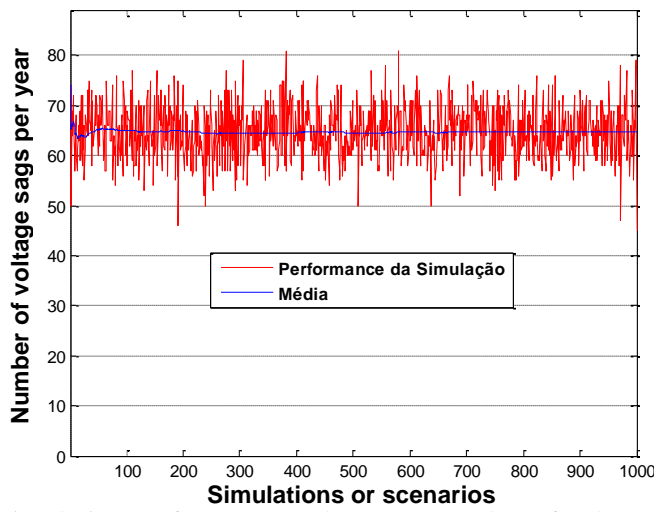

Fig. 11. Simulation performance and average number of voltage sags for 0 kVA DG at 9106 busbar.

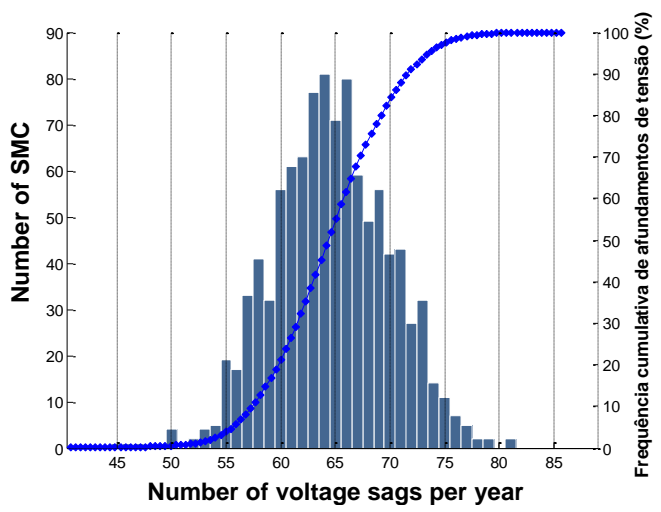

Fig. 12.Distribution and cumulative distribution of voltage sags at 9106 busbar with $0 \mathrm{kVA}$ DG.

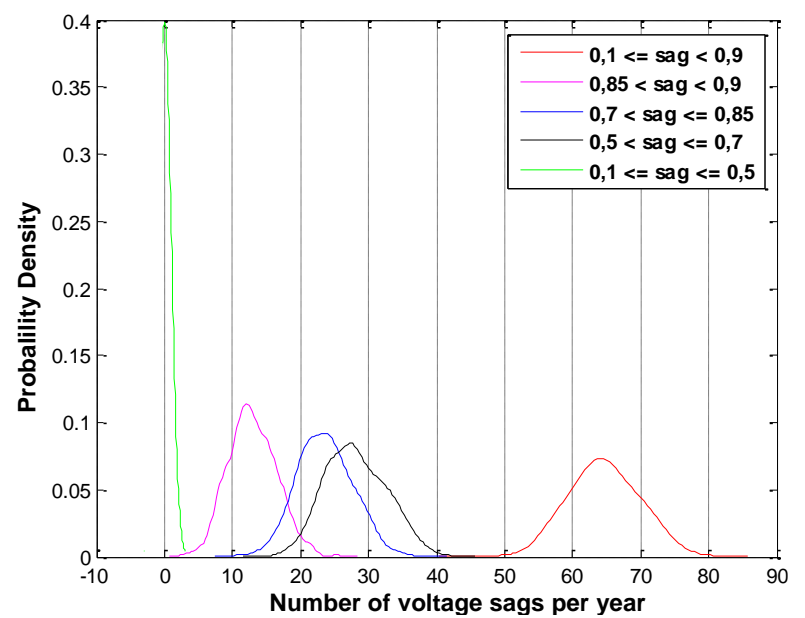

Fig. 13. Probability density of voltage sag classes for $0 \mathrm{kVA}$ DG at 9106 busbar.

The insertion of a 4,500 kVA DG next to 9106 busbar decreases the average number of expected voltage sags to approximately 43, as shown in Figs. 14-18. This represents a difference of 24 voltage sags compared to the case without DG. 


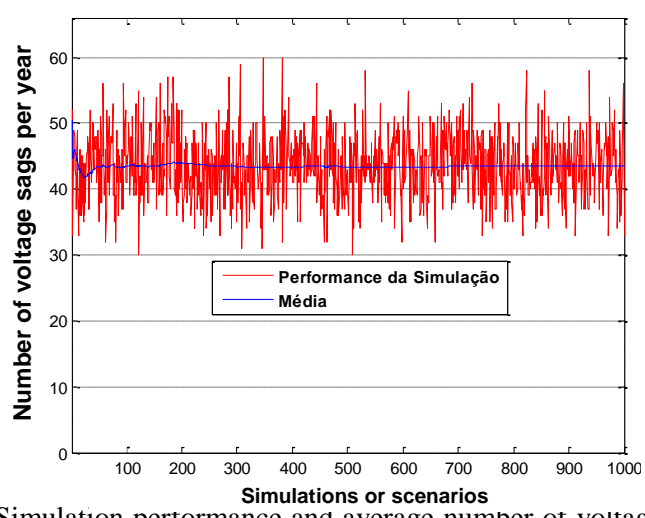

Fig. 14. Simulation perrormance ana average number or voltage sags for 4,500 kVA DG at 9106 busbar.

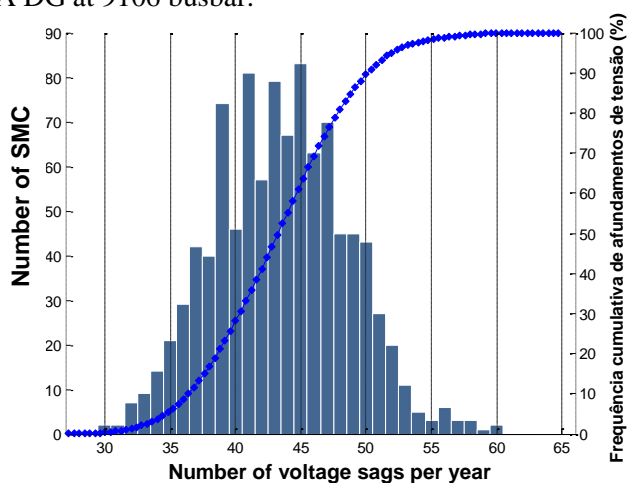

Fig. 15.Distribution and cumulatıve distribution of voltage sags for 4,500 kVA DG at 9106 busbar.

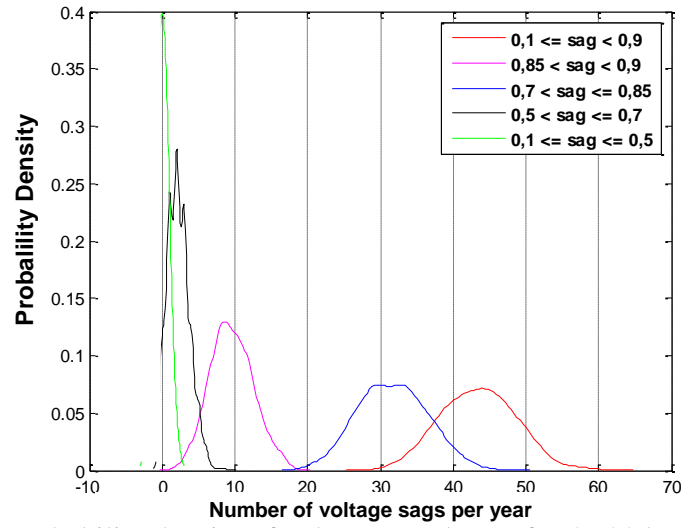

Fig. 16.Probability density of voltage sag classes for $4,500 \mathrm{kVA} \mathrm{DG}$ at 9106 busbar.

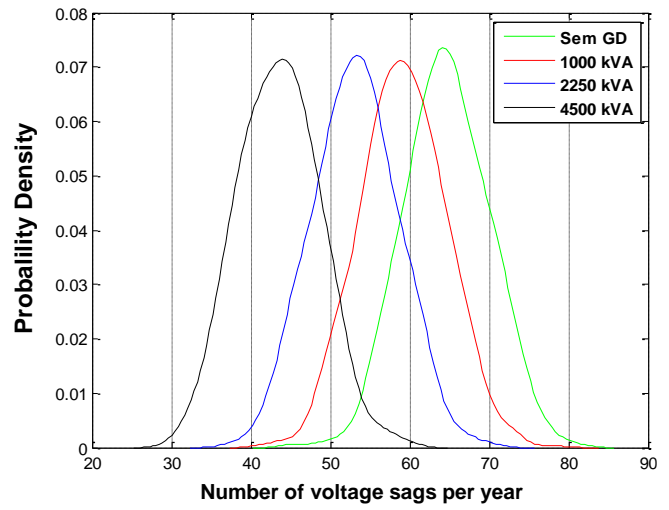

Fig. 17.Probability density of voltage sags for different levels of DG at 9106 busbar.

Table IV shows for each bar and each GD level the expected number of voltage sags in one year and shows that the two bars will be subjected to approximately the same amount of sags.

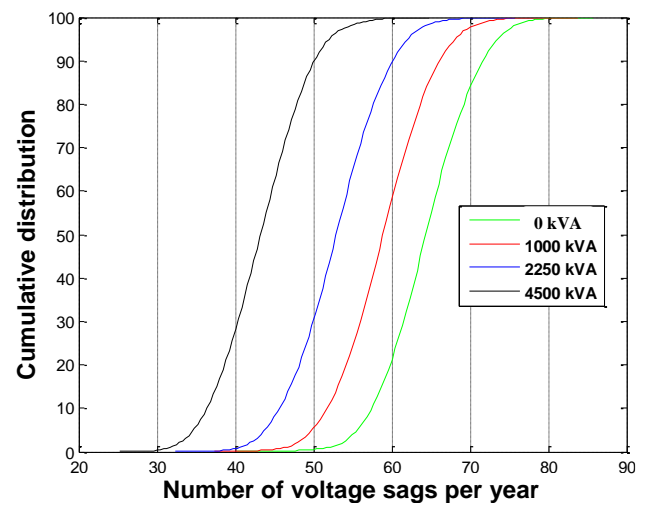

Fig. 18.Cumulative distribution curves of voltage sags for different DG DG at 9106 levels.

The impact of GD on the quantity of sinkings as a whole, as shown in Table IV, does not accurately provide the influence of such sources on the amplitude and consequently on the severity of such events. Therefore, Tables III and V also show the impact of GD on voltage sags classes for consumers B (9106) and $\mathrm{C}(9112)$.

TABLEIV

VOLTAGE SAG FREQUENCY VARIATION FOR ZERO AND 4,500 KVA DG IN BUSBAR 9112 AND 9106.

\begin{tabular}{c|c|c|c|c} 
& \multicolumn{4}{|c}{ Level DG (kVA) } \\
\hline Busbar & $\mathbf{0}$ & $\mathbf{1 , 0 0 0}$ & $\mathbf{2 , 2 5 0}$ & $\mathbf{4 , 5 0 0}$ \\
\hline $\mathbf{9 1 0 6}$ & 65 & 59 & 53 & 43 \\
\hline $\mathbf{9 1 1 2}$ & 67 & 59 & 53 & 43
\end{tabular}

Aiming provide general results in terms the DG level vs Scc of the network, was verified for this system that the number of severe sags, magnitude $0.5-0.7 \mathrm{pu}$, decreased by $91.96 \%$ at a point short-circuit lower (Client B - Busbar 9106), being more sensitive to inserting GD sources.

TABLE V

NUMBER OF VOLTAGE SAGS AT END-USER BUSBAR 9106 ACCORDING TO

\begin{tabular}{c|l|c|c|c|c}
\multirow{2}{*}{$\begin{array}{c}\text { DG levels } \\
(\text { kVA) }\end{array}$} & \multicolumn{5}{|c|}{ Voltage sag magnitude classes (p.u.) } \\
\cline { 2 - 6 } & $\mathbf{0 . 1 - 0 . 5}$ & $\mathbf{0 . 5 - 0 . 7}$ & $\mathbf{0 . 7 - 0 . 8 5}$ & $\mathbf{0 . 8 5 - 0 . 9}$ & $\mathbf{0 . 1 - 0 . 9}$ \\
\hline $\mathbf{0}$ & 0 & 28,1517 & 23,565 & 12,939 & 64,661 \\
\hline $\mathbf{1 0 0 0}$ & 0 & 23,198 & 24,734 & 11,224 & 59,156 \\
\hline $\mathbf{2 2 5 0}$ & 0 & 12,319 & 27,582 & 13,253 & 53,154 \\
\hline $\mathbf{4 5 0 0}$ & 0 & 2,263 & 31,679 & 9,549 & 43,491
\end{tabular}

TABLE VI

VOLTAGE SAG FREQUENCY VARIATION FOR ZERO AND 4,500 KVA DG.

\begin{tabular}{c|c|c|c|c|c}
$\begin{array}{c}\text { Voltage sag } \\
\text { magnitude } \\
\text { classes (p.u.) }\end{array}$ & $\mathbf{0 . 1 - 0 . 5}$ & $\mathbf{0 . 5 - 0 . 7}$ & $\mathbf{0 . 7 - 0 . 8 5}$ & $\mathbf{0 . 8 5 - 0 . 9}$ & $\mathbf{0 . 1 - 0 . 9}$ \\
\hline Variation (\%) & 0 & $-91,96$ & 34,43 & $-26,19$ & $-33,74$ \\
$\Delta N_{\text {sag }}=\left(\frac{N_{\text {sag }, 4500 \mathrm{kVA}}-N_{\text {sag }, 0 \mathrm{kVA}}}{N_{\text {sag }, 0 \mathrm{kVA}}}\right) \cdot 100$
\end{tabular}

Where:

$\mathbf{N}_{\text {sag, } 4500 k V A}$ Number of voltage sags for 4,500 kVA DG level;

$\mathrm{N}_{s a g, 0 k V A}$ Number of voltage sags for zero DG level.

Table $\mathrm{V}$ shows the relative variation of the number of voltage sags, according to the voltage sag magnitude classes, for minimum and maximum level of DG at 9106 busbar. The relative variation, $\Delta N_{s a g}$, is calculated by (3).

According to table $\mathrm{V}$ there was an increase in the number of voltage sags with magnitudes between $0.7-0.85$ p.u., which shows the impact of the network topology in some classes of 
voltage sags. In this case the Distributed Generation did not offer benefits for the reduction of voltage sags, and the main reason for this is the connection point (busbar 9106) in the system (network topology).

\section{Conclusion}

The paper shows the impact of DG and network topology on voltage sag magnitude and frequency for a sensitive end-user. Voltage sags indices were obtained by the simulation of shortcircuits. Long term simulation scenarios were obtained by the Monte Carlo method.

For each level of DG, the cumulative distribution function and the probability density curves for different classes of voltage sags were obtained. According to the results, the level of DG and network topology next to a sensitive end-user influences the total number of voltage sags and the number of voltage sags classified by classes of magnitude.

In general, it is shown that the greater the level of DG next to the end-user busbar, the smaller the number of voltage sags expected per year. Besides that, the most severe voltage sags become less frequent and the less severe voltage sags become more frequent with the increase of DG level (i.e., DG power rating).

In general, the client connected to the point of lowest level of short-circuit (Client B), there was a greater reduction in severe dips (i.e., class $0.5-0,7$ ) for the same level of DG connected at bar $380 \mathrm{~V}$.

However, most of the voltage sags, that is, those more frequent, occur at the point of lower level of short circuit. This type of study can influence the best point of location of a sensitive consumer, in order to avoid stops due to voltage sags, considering the level of GD, network topology and consumer sensitivity (voltage sags class).

\section{Acknowledgment}

For the realization of this work the authors thank CELG Generation and Transmission SA - CELG GT by prospective vision that has allowed them to use the software ANAFAS in the simulations.

The author also thanks the of technology college Senai Italo Bologna.

\section{References}

[1] M. H. J. Bollen, Understanding Power Quality Problems: Voltage Sags and Interruptions, McGraw-Hill, IEEE Press Series on Power Engineering, 2000.

[2] J. A. M. Velasco, J. M. Arnedo, "Distributed Generation Impact on Voltage Sags in Distributions Networks," in Proc. 9th International Conference on Electrical Power Quality and Utilization, Barcelona, Spain, 2007, pp. 1-6.

[3] H. S. Bronzeado et. al. "A Proposal for a National Nomenclature and Definitions of Terms Associated with Power Quality", in Proc.II Brazilian Seminar on Quality of Electricity, São Lourenço, Brazil, 1997, pp. 1-8. (In Portuguese)

[4] M. N. Moschakis, N. D. Hatziargyriou, "Analytical Calculation and Stochastic Assessment of Voltage Sags," IEEE Transactions on Power Delivery, vol. 21, no. 3, 2006, pp. 1727-1734.

[5] J. A. M. Velasco, J. M. Arnedo. "Voltage Sag Stochastic Prediction Using an Eletromagnetic Transient Program,"IEEE Transactions on Power Delivery, vol. 19, no.4, 2004, pp. 1975-
1982.

[6] J. V.Milanovic, M. T.Aung, C. P. Gupta."The Influency Of Fault Distribution on Stochastic Prediction of Voltage Sags,"IEEE Transactions on Power Delivery, vol. 20, no. 1, 2005.

[7] J. V.Milanovic, R. Gnativ, K. W. M. Chow, "The Influency Of Loading Conditions And Networks Topology On Voltage Sags,"Harmonics and Quality of Power, IEEE, Orlando, vol. 2, 2000, pp. 757-762.

[8] Y. S. Lim, G. Strbac, "Analytical Approach to Probabilistic Prediction of Voltage Sags on Transmission Networks,"IEE Proc. Gener. Transm. Distrib, vol. 149, no. 1, 2002, pp. 7-14.

[9] J. A. M. Velasco, J. M. Arnedo, "Voltage Sag Studies in Distribution Networks - Part II: Voltage Sag Assessment," IEEE Transactions on Power Delivery, vol. 21, no. 3, 2006, pp. 16791688.

[10] T. Ackermann, G. Andersson, L. Soder, "Distributed Generation: a definition”, Electrical Power Systems Research, vol. 57, no.3, 2001, pp. 195-204.

[11] C. T. Hsu, C. J. Fu, "Dispersed Generation Systems Impact on the Voltage Sags in Distribution Systems," in Proc. International Conference on Power System Technology, Chongqing, China, 2006, pp. 1-7.

[12] T. N. Boutsika, S. A. Papathanassiou, "Short-circuit calculations in networks with distributed generation,"Electrical Power Systems Research, vol. 78, no. 7, 2008, pp.1181-1191.

[13] Research Center Electricity - CEPEL, user manual analysis program simultaneous faults - ANAFAS, v. 4.4, Rio de Janeiro, Brazil, 2007. (In Portuguese)

[14] G. Olguin, D. Karlsson, R. C. Leborgne, "Stochastic Assessment of Voltage Sags (Dips): The Method of Fault Positions versus a Monte Carlo Simulation Approach," In Power Tech, IEEE, Rússia, 2005, pp. 1-7.

[15] J. M. C. Filho et. al, "Validation of voltage sag simulation tools: ATP and short-circuit calculation versus field measurements," IEEE Transactions on Power Delivery, vol. 23, no. 3, 2008, pp. 1472-1480.

[16] W. Freitas at. al, "Comparative Analysis Between Synchronous and Induction Machines for Distributed Generation Applications," IEEE Transactions on Power System, vol. 21, no. 1, 2006, pp. 301-311.

[17] ATP - Alternative Transients Program. User's Manual, 1996.

[18] P. M. Anderson, A. A. Fouad. Power System Control and Stability, IEEE Press Power Systems Engineering Series, 1st ed., Iowa State University Press, 1977.

[19] Procedures for distribution of electricity in the national grid system (PRODIST) - Module 8: power quality, ANEEL, 2008. (In Portuguese)

[20] Electromagnetic Compatibility (EMC) - Part 2: Environment Section 6: Voltage Dips and short interruptions on public electric power supply systems with statistical measurements results, IEC 61000-2-8, 2002.

[21] J. C. Cebrian, N. Kagan, "Hybrid Method to Assess Sensitive Process Interruption Costs Due to Faults in Electric Power Distribution Networks", IEEE Transactions on Power Delivery, vol. 25, pp. 1686 - 1696, 2010.

[22] Ramos, A. C. L.; Batista, A. J.; Domingues, E. G.; Calixto, W. P. A First Approach on the Fault Impedance Impact on Voltage Sags Studies, 2015. La Coruña, Spain, International Conference on Renewable Energies and Power Quality (ICREPQ'15).

[23]Ramos, A. C. L.; Batista, A. J.; Domingues, E. G.; Leborgne, R. C.; Calixto, W. P. A First Approach on the Impact of Distributed Generation on Voltage Sags Studies, 2014. Cordoba, Spain, International Conference on Renewable Energies and Power Quality (ICREPQ'14). 